\title{
Author Correction: Dynamical nonlinear memory capacitance in biomimetic membranes
}

\author{
Joseph S. Najem (1) 1,2, Md Sakib Hasan ${ }^{3}$, R. Stanley Williams (1) 4, Ryan J. Weiss ${ }^{3}$, Garrett S. Rose ${ }^{3}$, \\ Graham J. Taylor (10 ${ }^{1,5}$, Stephen A. Sarles ${ }^{1} \&$ C. Patrick Collier ${ }^{6}$
}

Correction to: Nature Communications https://doi.org/10.1038/s41467-019-11223-8, published online 19 July 2019

The original version of this Article contained an error in Fig. 3b, in which the $\mathrm{x}$-axis label incorrectly read 'Time (s)' rather than the correct ' $V(\mathrm{~V})$ '. This has been corrected in both the PDF and HTML versions of the Article.

Published online: 21 August 2019

\begin{abstract}
cc. and indicate if changes were made. The images or other third party material in this article are included in the article's Creative Commons license, unless indicated otherwise in a credit line to the material. If material is not included in the article's Creative Commons license and your intended use is not permitted by statutory regulation or exceeds the permitted use, you will need to obtain permission directly from the copyright holder. To view a copy of this license, visit http://creativecommons.org/licenses/by/4.0/.
\end{abstract}

(C) The Author(s) 2019

\footnotetext{
${ }^{1}$ Department of Mechanical, Aerospace and Biomedical Engineering, University of Tennessee, Knoxville, TN 37916, USA. ${ }^{2}$ Joint Institute for Biological Sciences, Oak Ridge National Laboratory, Oak Ridge, TN 37831, USA. ${ }^{3}$ Department of Electrical Engineering and Computer Science, University of Tennessee, Knoxville, TN 37916, USA. ${ }^{4}$ Department of Electrical and Computer Engineering, Texas A\&M University, College Station, TX 77840, USA. ${ }^{5}$ Bredesen Center for Interdisciplinary Research, University of Tennessee, Knoxville, TN 37996, USA. ${ }^{6}$ Center for Nanophase Materials Sciences, Oak Ridge National Laboratory, Oak Ridge, TN 37831, USA. Correspondence and requests for materials should be addressed to S.A.S. (email: ssarles@utk.edu) or to C.P.C. (email: colliercp@ornl.gov)
} 